\title{
Modified Harada-Mori and simple wet mount to determine hookworm infections in Yo Island urban area, Songkhla, Southern Thailand
}

\author{
Sirima Kitvatanachai ${ }^{1 *} \mathbb{B}$, Aree Taylor ${ }^{2}$, Pochong Rhongbutsri ${ }^{2}$ and Walter R. J. Taylor ${ }^{3,4}$
}

\begin{abstract}
Background: Hookworm was a previously dominant parasitic infection in Southern Thailand. The changing population to an aging society in Yo Island has never been investigated for intestinal parasites. This study aimed to estimate the prevalence of hookworm and intestinal parasitic infections on Yo Island, a small island in Songkhla Province of southern Thailand.

Methods: A cross-sectional study was conducted among volunteers aged 15 and above to give one stool sample that was screened by wet mount for intestinal parasites and the modified Harada-Mori culture (mHMFPC) which is adapted from HMFPC, using local plastic bag containers instead of test tubes for hookworm detection.

Results: Two hundred forty-seven volunteers (females $=160$ ) gave one stool. The highest participation was in age group higher than 60 years. Most were Buddhism (89.1\%), agriculturist (71.4\%), non-education (87.9\%), and income lower than 9000 baht (50.2\%). The prevalence of intestinal parasites was 13/247 (5.3\%) of which 6/247 (2.4\%) were positive for hookworm species Necator americanus. One volunteer was coinfected with hookworm and Strongyloides stercoralis and another with Endolimax nana and Blastocystis hominis. The mHMFPC detected more positive stool samples than wet mount and wet mount: 5 vs. 2.

Conclusions: Parasite prevalence was low in this urban community of mostly low-income village dwellers. The mHMFPC appeared better at detecting hookworm but numbers were small. Combined techniques are suitable for field use.
\end{abstract}

Keywords: Modified Harada-Mori, Simple wet mount, Yo island, Hookworm infections

\section{Background}

Hookworm is a neglected tropical disease (NTDs) that has a global distribution [1,2]. Overall, its prevalence tends to be more common in adults $[3,4]$. However, soil-transmitted helminth control programs in endemic countries focus on risk group of school-aged children (2-14 years). Hookworm is found at the highest intensities in adults, and hence, its abundance is not affected by treating only school-aged children [3, 4]. The adult hookworms attach to the small intestine where they feed

\footnotetext{
* Correspondence: sirima@rsu.ac.th; kitvatanachai@yahoo.com ${ }^{1}$ Faculty of Medical Technology, Rangsit University, Lak Hok, Pathumthani 12000, Thailand

Full list of author information is available at the end of the article
}

on blood and can cause iron-deficient anemia in individuals of all ages [5].

Over the last several decades, hookworm infection has and continues to be a significant public health problem in Thailand where studies have reported a prevalence of up to nearly $33 \%$ in schoolchildren [6-8]. One study in Nakhon Si Thammarat, southern Thailand, the mean hookworm infection rate in several primary school pupils aged 5 to $<12$ years was $32.7 \%$ [9]. This contrasted to a low rate of $8 \%$ in 324 healthy volunteers from the same province [10] and $15.8 \%$ in 2014 in Southern Thailand [8].

The diagnosis of hookworm rests on finding eggs in stool samples but, currently, there is no agreement

(C) The Author(s). 2019 Open Access This article is distributed under the terms of the Creative Commons Attribution 4.0 International License (http://creativecommons.org/licenses/by/4.0/), which permits unrestricted use, distribution, and 
regarding which test or combination of tests should be used as the "gold standard" $[11,12]$.

Direct wet mount of stool has a low sensitivity for detecting light helminthic infections [13]. In two studies, wet mount had detection rates of $18.8 \%$ vs. $24.7 \%$ for formalin-ether concentration (FEC) [14], and 48.9\% vs. 63.1 and $93.7 \%$ for FEC and Kato Katz tests, respectively [15]. Nuchprayoon et al. (2009) suggest that the simple direct smear is insufficiently sensitive to be used alone for stool parasite screening [16].

The sensitivity for detecting hookworm and other helminths is generally higher using the Harada-Mori filter paper culture (HMFPC). It achieved a detection rate for hookworm of $45.8 \%$ vs. $41.7 \%$ by FEC and $25.0 \%$ by simple smear in Burmese migrant workers in Thailand [16]. HMFPC also has the advantage of being able to detect third stage larvae of hookworm and Strongyloides stercoralis from culture and at this stage the species of hookworm can be identified [17]. The modified (m) HMFPC, using local plastic bag containers to replace the test tube which is cheap ( $<0.03$ USD), easy, and simple for field culture and reported higher prevalence of $11.3 \%$ compared to direct smear $(6.9 \%)$ and FEC (10.1\%) [18].

There are no data on the prevalence of intestinal parasites on Yo Island in southern Thailand. Therefore, we conducted a prevalence survey of hookworm and other intestinal parasites using the mHMFPC method and wet smear to inform the parasitic disease control program.

\section{Materials and methods}

This was a cross-sectional community survey that was conducted from August to October, 2015 in Yo Island, it is a small island in Songkhla Lake in southern Thailand, approximately $15 \mathrm{~km}$ from Muang Songkhla that is connected to the Thai mainland via the bridge. The majority of the 4459 population live in 9 villages and make a living from agriculture, fishing, and running small businesses, e.g., hand-woven fabric. The island has two health centers [19].

The inclusion criteria were male or females aged $\geq 15$ years, living in 9 villages on the island, who had voluntarily provided informed assent, had written informed consent, and provided enough stool for examination. Participants aged $<15$ years living outside the area and providing an insufficient amount of stool were excluded. The sample size was calculated using single population proportion formula; assuming expected prevalence of $16 \%$ [8], 95\% confidence level, $5 \%$ margin of error. The sample size was finally calculated to be 206 .

Health workers distributed labeled, clean plastic containers to enrolled villagers and instructed them on how to collect the stool samples. One stool sample was collected from each participant. A structured questionnaire was used to collect data on demographics, occupation, sanitation, and hygiene practices.

Wet mount preparations were prepared in accordance with standard protocols [20]. One to two milligrams of stool were put on a slide, $0.85 \%$ NSS and $1 \%$ iodine were used for wet mount. The mHMFPC was modified from Harada and Mori [21]. Briefly, $2 \mathrm{~g}$ of fresh stool were placed on a folded strip of filter paper $(30 \mathrm{~mm} \times 150 \mathrm{~mm})$, which was then placed in a $30 \mathrm{~mm} \times 200 \mathrm{~mm}$ plastic tube containing $5 \mathrm{~mL}$ of sterile distilled water and incubated at room temperature $\left(25-35^{\circ} \mathrm{C}\right)$ for 7 days. $0.5 \mathrm{~mL}$ formaldehyde was then added and the tube was centrifuged at $2000 \mathrm{r} / \mathrm{min}$ for $5 \mathrm{~min}$. The sediment was examined under the microscope. All third stage larvae were identified by species level based on their morphological characteristics $[18,22]$.

All samples were independently examined in a blinded fashion by two microscopists. Expert parasitologists reread all positive slides and $10 \%$ of randomly selected negative slides.

Data were analyzed descriptively (frequencies and percentage) using IBM SPSS Version 21.0. The prevalence of hookworm infections was determined by taking combined results of wet smear and mHMFPC. Every individual with at least one positive test was considered as truly infected.

\section{Results and discussion}

A total of 247 villagers were able to provide stool samples for both identification methods. Most were Thai nationals, age $>50$ years $(>55 \%$ of samples $)$ and the female to male ratio was 1.9:1 (Table 1). The vast majority were Buddhist with no formal education; only $2 \%$ had a basic level of schooling. Just over $70 \%$ were agriculturist (gardeners or fishermen) while the rest had diverse occupations. Half the participants were on a low income, earning < 9000 Baht (USS 270)/month (Table 1). The characteristics of the six hookworm-positive individuals are summarized in Tables 1 and 2. They all had and used toilets, and all wore shoes when going out, usually sandals $(n=4) ; 5$ of them reported that they had never been dewormed (Table 2).

Combining both methods, the total number of villagers with positive stool samples was 13 for a prevalence of $5.3 \%$ (Table 3). Of these, 6 (2.4\%) were infected with hookworm, including one mixed infection with Strongyloides stercoralis. Our study has shown that in Yo Island, that has an aging population and this is why we focused our sample on volunteers aged 15 and above. The prevalence of hookworm infection and other parasitic infections was low, just under 2.5 and $5.5 \%$, respectively. Our data contrast with other studies from Thailand. One subnational random survey in districts from 14 provinces in southern Thailand reported an overall hookworm prevalence of $15.8 \%$ by FEC [5] while in 2002 primary school children 
Table 1 Socio-demographic characteristics of the 247 participants and hookworm infections in Yo Island

\begin{tabular}{|c|c|c|}
\hline Demographic characteristics & No. (\%) & No. of HW infections (\%) \\
\hline \multicolumn{3}{|l|}{ Gender } \\
\hline Male & $84(34.0)$ & $3(3.6)$ \\
\hline Female & $160(64.8)$ & $3(1.9)$ \\
\hline No information & $3(1.2)$ & \\
\hline \multicolumn{3}{|l|}{ Age groups (years) } \\
\hline $15-20$ & $5(2.0)$ & $1(20)$ \\
\hline $21-30$ & $16(6.5)$ & \\
\hline $31-40$ & $30(12.2)$ & $1(3.3)$ \\
\hline $41-50$ & 46 (18.6) & \\
\hline $50-60$ & $67(27.1)$ & \\
\hline$>60$ & $70(28.3)$ & $4(5.7)$ \\
\hline No answer & $13(5.3)$ & \\
\hline \multicolumn{3}{|l|}{ Religion } \\
\hline Buddhism & $220(89.1)$ & $6(2.7)$ \\
\hline Islam & $2(0.8)$ & \\
\hline No answer & $25(10.1)$ & \\
\hline \multicolumn{3}{|l|}{ Education } \\
\hline No education & $217(87.9)$ & $5(2.3)$ \\
\hline Primary and secondary school & $5(2.0)$ & $1(20.0)$ \\
\hline No answer & $25(10.1)$ & \\
\hline \multicolumn{3}{|l|}{ Occupation } \\
\hline Agriculturist & $105(71.4)$ & $2(1.9)$ \\
\hline Housewife & $15(6.07)$ & $1(6.7)$ \\
\hline Employee & $30(12.2)$ & $2(6.7)$ \\
\hline Government servant/retired & 9 (3.6) & \\
\hline Hairdresser & $1(0.4)$ & \\
\hline Student & $7(2.8)$ & $1(14.3)$ \\
\hline Engineer & $1(0.4)$ & \\
\hline Private business & $3(1.2)$ & \\
\hline Shop keeper & $21(8.5)$ & \\
\hline Weaver & $9(3.6)$ & \\
\hline No answer & 46 (18.6) & \\
\hline \multicolumn{3}{|l|}{ Income (Baht) } \\
\hline$<9000$ & $124(50.2)$ & $4(3.2)$ \\
\hline $9001-16,000$ & $30(12.2)$ & $1(3.3)$ \\
\hline $16,001-30,000$ & $16(6.5)$ & \\
\hline$>30,000$ & $5(2.0)$ & \\
\hline No answer & $72(29.1)$ & $1(1.4)$ \\
\hline
\end{tabular}

from Nakhon Si Thammarat Province had a hookworm prevalence of $\sim 20 \%$ by the Kato-Katz technique [8]. Hookworm infection in villagers from three districts in Krabi Province was $15.1 \%$ combining simple smear, mHMFPC, and mFEC in 2012 [17].
Table 2 Sanitation and hygiene practice of the 247 participants and hookworm infections

\begin{tabular}{lll}
\hline Sanitation and hygiene practice & No. (\%) & No. of HW infections (\%) \\
\hline Sources of drinking water & $5(2.0)$ & $1(20.0)$ \\
Rain drinking & $70(28.3)$ & $1(1.4)$ \\
Tap water & $121(49.0)$ & $3(2.5)$ \\
Bottled water & $15(6.1)$ & $1(6.7)$ \\
Natural sources & $36(14.6)$ & \\
No answer & & \\
Toilet & $239(2.0)$ & $6(2.5)$ \\
Have & $8(14.6)$ & \\
No answer & & \\
Using toilet when at work & $236(95.6)$ & $6(2.5)$ \\
Yes & $2(0.8)$ & \\
No & $9(3.6)$ & \\
No answer & & \\
Wear shoes & $235(95.1)$ & $6(2.6)$ \\
Yes & $2(0.8)$ & \\
No & $10(4.1)$ & \\
No answer & & \\
Type of shoes when going to work & $141(57.1)$ & $6(4.3)$ \\
Sandal & $44(17.8)$ & \\
General shoes & $26(10.5)$ & \\
Boots & $36(14.6)$ & \\
No answer & & \\
No ho and before eating and drinking & \\
\hline
\end{tabular}

Table 3 The prevalence of intestinal helminths and hookworm in 247 Yo Island participants

\begin{tabular}{ll}
\hline Intestinal parasites & No. of infected (\%) \\
\hline Giardia lamblia & $1(0.4)$ \\
Blastocystis hominis & $1(0.4)$ \\
Endolimax nana & $3(1.2)$ \\
Strongyloides stercoralis & $1(0.4)$ \\
Hookworm & $5(2.0)$ \\
Mixed infection & \\
$\quad$ Strongyloides stercoralis and hookworm & $1(0.4)$ \\
$\quad$ E. nana and B. hominis & $1(0.4)$ \\
Total & $13(5.3)$ \\
\hline
\end{tabular}


Table 4 Prevalence of hookworm and Strongyloides stercoralis by simple wet mount and mHMFPC

\begin{tabular}{llll}
\hline Parasites & Wet mount & mHMFPC & Total \\
\hline Hookworm & $2(0.8)$ & $5(2.0)$ & $6(2.4)$ \\
Strongyloides stercoralis & $1(0.4)$ & $1(0.4)$ & $2(0.8)$ \\
\hline
\end{tabular}

Ours was the first intestinal parasite survey in Yo Island, which has seen increased development and urbanization over recent years. Better quality infrastructure, higher living standards with improved sanitation and personal hygiene, increasing age and a good health promotion infrastructure probably account for the low prevalence of hookworm and other parasites; such low rates are usually associated with urban environments in Thailand [23].

Only soil-transmitted helminths, hookworm, and Strongyloides stercoralis were found in this area. No foodborne helminths were detected, and this is probably due to good eating practice and the avoidance of raw food; indeed no one reported eating raw food (the information by health center staff).

We used the simple wet mount and the mHMFPC to determine the prevalence of intestinal parasite and hookworm infection. All positive wet mount stools were also positive by mHMFPC. The latter detected 5 cases of hookworm vs. 2 for wet mount (Table 4). The direct wet mount is useful for the observing motile protozoan trophozoites but is not recommended as the sole diagnostic test for routine stool examination because of its low sensitivity [13-15]. Nevertheless, it is easy to perform, cheap and is time-saving. In field studies, mHMFPC is a low-cost technique [<3 Baht (USD 0.09)/test], easy to perform, and has a high sensitivity (75.3-91.6\%) for detecting hookworm $[16,24]$. In our study, mHMFPC detected more hookworm than wet mount ( 2 vs $0.8 \%$ ) and combining both techniques increased detection rates. Therefore, we believe that both techniques should be used in field studies.

All six cases of hookworm infection were Necator americanus. The identified hookworm larvae were those of $N$. americanus (100\%), which is the dominant species in SE Asia [17]. Anantaphruti et al. showed $99.9 \%$ of hookworms were $N$. americanus vs. $0.1 \%$ for $A$. duodenale in southern Thailand [9]. Of the two, N. americanus is less pathogenic, with $0.02 \mathrm{ml}$ of blood loss per day compared to $0.1 \mathrm{~mL}$ for $A$. duodenale [25].

\section{Conclusions}

We demonstrated a low prevalence of hookworm and other parasites in a Thai population living on an island experiencing rapid economic development, suggesting good control of soil-transmitted helminths. Sensitivity was improved by the two simple and cheap techniques. Additional parasitic prevalence studies across a wider age spectrum to identify high-risk groups and tailor appropriate control efforts.

\section{Acknowledgements}

The authors give grateful thanks to Chatsuda Pannak, Thanapa Choeysakhon, Piyakorn Jereyapradub, Pattaraporn Sittisornchai, and Atchara Thongkum for their assistance in processing and examining the stool samples. We are grateful to the staff of health-promoting hospitals for arranging the room for specimen collection and processing. Additionally, we would like to thank all health volunteers and study participants.

\section{Funding}

The research project was not funded by any organization.

Availability of data and materials

All the data are available from the corresponding author upon request.

\section{Authors' contributions}

SK designed, analyzed, and interpreted the study, and wrote the manuscript. AT and PR assisted with design and interpretation. WRJT assisted with data interpretation and critically revised the manuscript. All authors read and approved the final manuscript.

\section{Ethics approval and consent to participate}

Ethical clearance was obtained from the Human Ethics Committee of Rangsit University, Pathumthani, Thailand (ethical clearance no. RSEC23/2557). Written informed consent and answered questionnaires were obtained from every participant. All participants identified with intestinal parasite infections were informed by health-promoting hospital staff and arranged to meet the doctor at the hospital for treatment depending on the type of species identified.

Consent for publication

Not applicable.

\section{Competing interests}

The authors declare that they have no competing interests.

\section{Publisher's Note}

Springer Nature remains neutral with regard to jurisdictional claims in published maps and institutional affiliations.

\section{Author details}

'Faculty of Medical Technology, Rangsit University, Lak Hok, Pathumthani 12000, Thailand. ${ }^{2}$ Department of Preclinical Science, Faculty of Medicine, Thammasat University, Lak Hok, Pathumthani 12120, Thailand. ${ }^{3}$ Mahidol Oxford Tropical Medicine Research Unit, Bangkok, Thailand. ${ }^{4}$ Centre for Tropical Medicine and Global Health, University of Oxford, Oxford, UK.

Received: 18 January 2019 Accepted: 9 April 2019

Published online: 24 April 2019

\section{References}

1. Pullan RL, Brooker SJ. The global limits and population at risk of soiltransmitted helminth infections in 2010. Parasit Vectors. 2012;5(1):81.

2. World Health Organization. In: Neglected tropical diseases. 2016. https://www.who.int/neglected_diseases/diseases/en/. Accessed 9 Feb 2016.

3. Anderson RM, Schad GA. Hookworm burdens and faecal egg counts; an analysis of the biological basis of variation. Trans R Soc Trop Med Hyg. 1985;79(6):812-25.

4. Turner H, Truscott J, Bettis A, Shuford K, Dunn J, Hollingsworth T, et al. An economic evaluation of expanding hookworm control strategies to target the whole community. Parasite Vectors. 2015;5(1):81.

5. Olsen A, Magnussen P, Ouma JH, Andreassen J, Friis $\mathrm{H}$. The contribution of hookworm and other parasitic infection to haemoglobin and iron status among children and adults in western Kenya. Tran R Soc Trop Med Hyg. 1998;92:643-9.

6. Jongsuksantigul P, Choeychomsri W, Techamontrigul P, Jerdit P, Suruthanavanith $P$. Study on prevalence and intensity of intestinal helminthiasis and opisthorchiasis in Thailand. J Trop Med Parasitol. 1992;15:80-95.

7. Jongsuksantigul P. Soil-transmitted helminthiases control in Thailand. In: Lecture note presented at ACIPAC international training course on schoolbased malaria and soil transmitted helminthiases control for programme 
managers at the Faculty of Tropical Medicine, Mahidol University, Bangkok, Thailand; 2002.

8. Wongsaroj T, Nithikathkul C, Rojkitikul W, Nakai W, Royal L, Rammasut P. Nation survey of helminthiasis in Thailand. Asian Biomed. 2014;8:779-83.

9. Anantaphruti MT, Maipanich W, Muennoo C, Pubampen S, Sanguankiat S. Hookworm infections of schoolchildren in southern Thailand. Southeast Asian J Trop Med Public Health. 2002;33(3):468-73.

10. Punsawad C, Phasuk N, Bunratsami S, Thongtup K, Siripakonuaong N, Nongnaul S. Prevalence of intestinal parasitic infection and associated risk factors among village health volunteers in rural communities of southern Thailand. BMC Public Health. 2017;17:564.

11. Knopp S, Rinaldi L, Khamis IS, Stothard JR, Rollinson D, Maurelli MP, et al. A single FLOTAC is more sensitive than triplicate Kato-Katz for the diagnosis of low-intensity soil-transmitted helminth infections. Trans R Soc Trop Med Hyg. 2009;103:347-54

12. Utzinger J, Rinaldi L, Lohourignon LK, Rohner F, Zimmermann MB, Tschannen $A B$, et al. FLOTAC: a new sensitive technique for the diagnosis of hookworm infections in humans. Trans R Soc Trop Med Hyg. 2008;102:84-90.

13. Levecke B, De Wilde N, Vandenhoute E, Vercruysse J. Field validity and feasibility of four techniques for the detection of Trichuris trichiura in Simians: a model for monitoring drug efficacy in public health. PLoS Negl Trop Dis. 2009;3(1):e366.

14. Mengist HM, Demeke G, Zewdie O, Belew A. Diagnosis performance of direct wet mount microscopy in detecting intestinal helinths among pregnant women attending ante- natal care (ANC) in east Wolloga, Oromia, Ethiopia. BMC Res Notes. 2018;11:276.

15. Yimer M, Hailu T, Mulu W, Abera B. Evaluation performance of diagnostic methods of intestinal parasitosis in school age children in Ethiopia. BMC Res Notes. 2015;8:820.

16. Nuchprayoon S, Sanprasert V, Kaewzaithim S, Saksirisampant W. Screening for parasitic infections among Myanmar migrant workers in Thai food industry: a high-risk transmission. J Immigrant Minority Health. 2009;11:115-21.

17. World Health Organization. Intestinal protozoan and helminthic infections. In: Technical Report Series 666. Geneva; 1981. https://apps.who.int/iris/ handle/10665/41519. Accessed 9 Mar 2016.

18. Kitvatanachai S, Taylor A, Rhongbutsri P, Pongstaporn W. Determine the prevalence of intestinal and soil-transmitted helminths using different copromicroscopic techniques in Krabi Province, Thailand. Asian Pac J Trop Dis. 2017;7(12):719-23.

19. Ko Yo District administration. Ko Yo. http://www.kohyor.go.th/content/ information/1. Accessed 9 Feb 2016.

20. World Health Organization. Basic laboratory methods in medical parasitology. Geneva: World Health Organization; 1991.

21. Harada T, Mori O. A new method for culturing hookworm. Yonago Acta Med. 1995; 1(3):177-9.

22. Pawlowski ZS, Schad GA, Stott GJ. Hookworm infection and anaemia. Approaches to prevention and control. Geneva: World Health Organization; 1991. p. 96.

23. Kitvatanachai S, Boonsilp S, Watanasatitarpa S. Intestinal parasitic infections in Srimum suburban area o Nakhon Ratchasima Province, Thailand. Trop Biomed. 2008;25(3):237-42

24. World Health Organization. Guidelines for the evaluation of soil transmitted helminthiasis and schistosomiasis at the community level. Geneva: Schistosomiasis and intestinal parasite unit, division of control of tropical diseases, World Health Organization, (WHO/CTD/SIP/98.1); 1998.

25. Shahid SB, Wazib A, Chowdhury A, Shamsuzzaman SM, Mamun KZ. Identification of hookworm species in stool by Harada Mori culture. Bangladesh J Med Microbiol. 2010;4(02):3-4.

Ready to submit your research? Choose BMC and benefit from:
- fast, convenient online submission
- thorough peer review by experienced researchers in your field
- rapid publication on acceptance
- support for research data, including large and complex data types
- gold Open Access which fosters wider collaboration and increased citations
- maximum visibility for your research: over 100M website views per year
At BMC, research is always in progress.
Learn more biomedcentral.com/submissions

